05

\title{
Свойства короткозамкнутых ВТСП катушек
}

\author{
(C) М.В. Козинцева, ${ }^{1}$ А.М. Бишаев, ${ }^{1}$ А.А. Буш, ${ }^{1}$ М.Б. Гавриков, ${ }^{2}$ К.Е. Каменцев, ${ }^{1}$ Н.А. Нижельский, ${ }^{4}$ \\ В.В. Савельев, ${ }^{2,3}$ А.С. Сигов ${ }^{1}$ \\ ${ }^{1}$ Московский технологический университет, \\ 119454 Москва, Россия \\ ${ }^{2}$ Институт прикладной математики им. М.В. Келдыша РАН, \\ 125047 Москва, Россия \\ ${ }^{3}$ Национальный исследовательский ядерный университет „МИФИ“, \\ 115409 Москва, Россия \\ ${ }^{4}$ Московский государственный технический университет им. Н.Э. Баумана, \\ 105005 Москва, Россия \\ e-mail: kozintseva@mirea.ru
}

(Поступило в Редакцию 31 мая 2016 г.)

Исследованы свойства короткозамкнутых многовитковых сверхпроводящих катушек, изготовленных из высокотемпературной сверхпроводящей (BTCП) ленты фирмы SUPER POWER, имеющих несверхпроводящие контакты. Захваченный ВТСП катушками магнитный поток измерен при различных значениях магнитного поля намагничивающего соленоида. По максимальным значениям захваченного ВТСП катушками поля были определены экспериментальные значения критического тока в них. Его величина составила $\sim 50 \%$ от паспортного значения для данной ВТСП ленты. Экспериментально определен диапазон изменения внешнего поля, в котором ВТСП катушки сохраняют захваченный магнитный поток. Полученные результаты указывают на возможность создания магнитных систем с левитирующими магнитными катушками из ВТСП ленты, в которых управление левитацией осуществляется без использования обратных связей.

DOI: 10.21883/JTF.2017.06.44509.1911

\section{Введение}

В ловушках-Галатеях плазма удерживается вблизи нуля магнитного поля ловушки [1,2], а коаксиальные магнитные катушки („миксины“ [1]), формирующие магнитную корку ловушки, погружены в плазму. Для удержания высокотемпературной плазмы магнитная система ловушки-Галатеи должна состоять из нескольких коаксиальных катушек-колец, левитирующих в плазменном объеме.

В левитирующих системах, разработанных в США $[3,4]$ и Японии $[5,6]$, в поле закрепленной сверхпроводящей (LDX, США), либо несверхпроводящей (RT-1, Япония) катушки левитирует одна катушка, формирующая поле магнитного диполя. Устойчивость левитирующих состояний катушки обеспечивается системой обратных связей [3-6].

Простейшей магнитной системой, в которой формируется характерная для ловушек-Галатей область нуля магнитного поля, является левитирующий квадруполь, состоящий из двух коаксиальных катушек с током одного направления. Состояния равновесия катушек квадруполя, левитирующих в поле закрепленной сверхпроводящей (либо несверхпроводящей) катушки, должны быть устойчивыми относительно: 1) вертикальных смещений их плоскости вдоль общей оси; 2) угла отклонения их оси от общей оси магнитной системы; 3) радиальных смещений их плоскости.

В [7-12] получены аналитические зависимости потенциальной энергии систем, в которых два (либо одно) сверхпроводящих кольца левитируют в поле закрепленного кольца (сверхпроводящего или несверхпроводящего). Локальные минимумы такой зависимости соответствуют устойчивым состояниям равновесия левитирующих колец. ${ }^{1}$ При выводе зависимостей предполагалось, что сверхпроводящие кольца сохраняют захваченный магнитный поток, кольца (либо катушки) являются тонкими, а поле силы тяжести - однородным. Таким образом, в [7-12] показано, что устойчивые левитирующие состояния в таких системах могут осуществляться без применения обратных связей.

Кроме того, применение аналитических зависимостей в силу их общности ограничено лишь предположениями, сделанными при их выводе. Это позволяет облегчить и удешевить проведение поисковых экспериментов с лабораторной моделью левитирующего квадруполя и для их выполнения использовать недорогие ВТСП кольца (либо тонкие короткозамкнутые ВТСП катушки) небольших размеров. Это замечание относится и к демонстрационному устройству для их осуществления, описанному в [8].

Аналитические зависимости для потенциальной энергии были получены в [7-12] для тонких колец. Кроме того, расчеты по этим зависимостям показали, что устойчивые левитирующие состояния двух сверхпроводящих колец в поле закрепленного третьего кольца существуют для сверхпроводящих колец с сильно различающимися диаметрами [8]. Однако использованные в [7-10]

${ }^{1}$ В [7-12] рассмотрена устойчивость левитирующих колец относительно вертикальных смещений и угла отклонения их осей. 
ВТСП кольца, полученные методом MTG (melt textured growth) [13], не являются тонкими и имеют близкие размеры. Поэтому для экспериментов по левитации были изготовлены короткозамкнутые многовитковые катушки различного диаметра из ВТСП ленты (далее для краткости - ВТСП катушки) [10-12]. В отличие от ВТСП колец катушки из ВТСП ленты не обладают бесконечной проводимостью. Использование таких катушек в экспериментах по левитации возможно только при точном знании их магнитных и электрических характеристик.

\section{1. Конструктивные и магнитные параметры ВТСП катушек}

Для экспериментов по левитации из ВТСП ленты типа SCS4050-i-AP 2G HTS (фирма-изготовитель SUPER POWER [14]) было изготовлено четыре многовитковые короткозамкнутые катушки (рис. 1). Их параметры, а также параметры ВТСП кольца Ø31 mm [8], изготовленного с помощью метода MTG, даны в таблице. В [8] указывалось, что для этого ВТСП кольца Ø31 mm захваченный им магнитный поток возрастал пропорционально увеличению силы тока в витках намагничивающего соленоида и при токе $50 \mathrm{~A}$ в его витках достигал значения $3.2 \cdot 10^{-5} \mathrm{~Wb}$. Однако известно, что многократное термоциклирование с использованием жидкого азота как охлаждающего агента вызывает постепенную деградацию сверхпроводящих характеристик ВТСП колец [15]. Поэтому перед проведением новых экспериментов по левитации необходимо заново исследовать их магнитные свойства. Как видно из таблицы, максимальное значение магнитного потока, захваченного ВТСП кольцом $\varnothing 31 \mathrm{~mm}$, снизилось до значения $1.3 \cdot 10^{-5} \mathrm{~Wb}$. Причем выход захваченного магнитного потока на насыщение начинается уже при токе $20 \mathrm{~A}$ в витках соленоида (захваченный поток при этом токе равен $0.90 \cdot 10^{-5} \mathrm{~Wb}$ ).

В таблице приняты следующие обозначения: № - номер, присвоенный ВТСП катушке (№ 1-№ 4), либо ВТСП кольцу (№ 5) для ее (его) идентификации; $D_{\text {ext }}$ и $D_{\text {int }}-$ внешний и внутренний диаметры ВТСП катушки (либо ВТСП кольца); $h-$ их высота, $N-$ число витков намотки; $m-$ масса катушки без корпуса; $I_{C P}-$ максимальный критический ток ВТСП ленты данного типа по паспорту; $I_{C E X}-$ значение критического тока

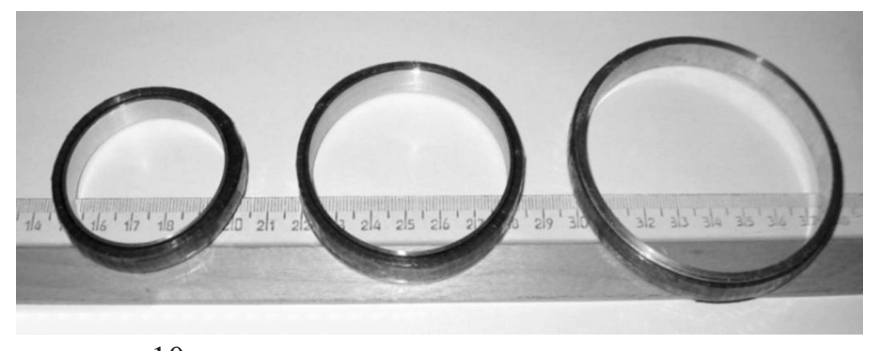

$10 \mathrm{~cm}$

Рис. 1. Фото короткозамкнутых ВТСП катушек.

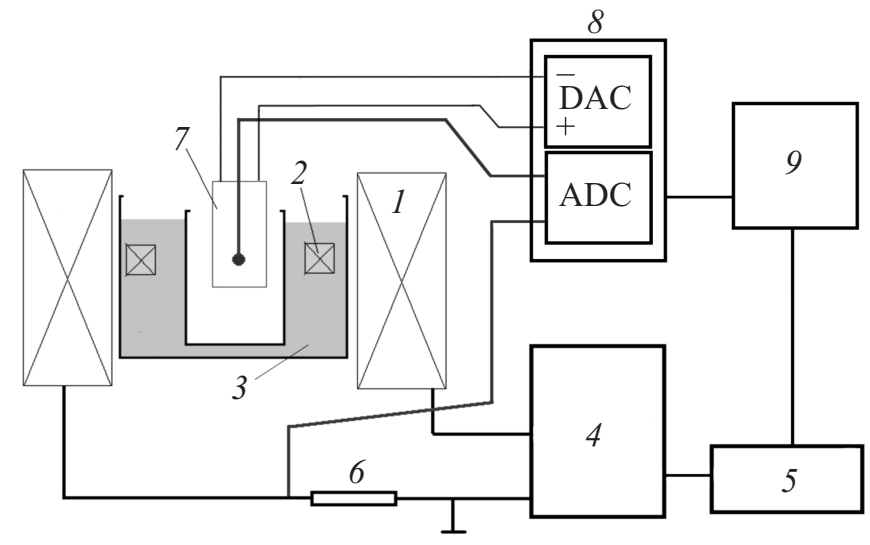

Рис. 2. Схема экспериментальной установки.

в ВТСП ленте, полученное экспериментально; $\Phi_{\max }-$ максимальное значение захваченного потока (через один виток); $\Psi_{\max }$ - максимальное значение захваченного потокосцепления; $\tau$ - постоянная времени спада магнитного поля ВТСП катушки.

Для изготовления катушек применялась ВТСП лента шириной $4 \mathrm{~mm}$ в изоляции из каптона. Длина спая и температурный режим пайки выбирались в соответствии с рекомендацией фирмы Super Power [14]. Катушки были изготовлены следующим образом: отрезался кусок ВТСП ленты необходимой длины; провод разрезался на два равных куска; концы кусков паялись между собой „внахлест“ („lap joint““ - [14]); начиная от этого спая, наматывались две обмотки на цилиндрический шаблон; наружные концы обмоток паялись внахлест.

Для придания катушкам механической прочности, исключения механических повреждений ВТСП провода для каждой катушки был изготовлен составной корпус из дюралюминия. Он состоял из кольцевого каркаса с внешним диаметром, равным внутреннему диаметру ВТСП катушки $D_{\text {int }}^{2}$ (на рис. 1 даны фото ВТСП катушек с этим каркасом), и крышки, которая вставлялась в этот каркас. Это позволяет в экспериментах по левитации использовать катушку с разными значениями масс.

Установка для исследования магнитных свойств ВТСП катушек и колец приведена на рис. 2. Она состоит из соленоида 1 ; исследуемой ВТСП катушки 2, размещенной в центральном сечении соленоида в стакане из пластика, в который заливался жидкий азот 3; источника питания соленоида типа Горн-К 4 с пультом управления 5; шунта 6 для измерения тока в витках соленоида; микросхемы 7 с линейным датчиком Холла, который располагается в центре катушки в теплоизоляционном стакане; крейт модуля фирмы „L-card“ 8, обеспечивающего питание микросхемы датчика Холла и запись в цифровом формате сигналов с датчика Холла и с шунта 6; компьютера 9. Соленоид 1 для намагничивания ВТСП катушек (либо колец) имел внутренний диаметр $100 \mathrm{~mm}$. Величина магнитного поля в

\footnotetext{
${ }^{2}$ См. таблицу.
} 
Параметры короткозамкнутых ВТСП катушек (№ 1-4) и ВТСП кольца (№ 5)

\begin{tabular}{c|c|c|c|c|c|c|c|c|c|c}
\hline № & $D_{\text {ext }}, \mathrm{mm}$ & $D_{\text {int }}, \mathrm{mm}$ & $h, \mathrm{~mm}$ & $N$ & $m, \mathrm{~g}$ & $I_{C P}, \mathrm{~A}$ & $I_{C E X}, \mathrm{~A}$ & $\Phi_{\max }, \mathrm{mWb}$ & $\Psi_{\max }, \mathrm{mWb}$ & $\tau, \mathrm{min}$ \\
\hline 1 & 56 & 48 & 8.5 & 24 & 15.3 & 135 & 71.3 & 0.083 & 2.0 & 35.2 \\
2 & 66 & 60 & 9.0 & 20 & 15.3 & 114 & 54.3 & 0.065 & 1.3 & 20.0 \\
3 & 66 & 60 & 9.0 & 19 & 14.5 & 135 & 70.4 & 0.097 & 1.85 \\
4 & 82 & 77 & 9.0 & 19 & 17.5 & 114 & 58.7 & 0.084 & 1.6 & 17.9 \\
5 & 31 & 15 & 3 & - & 9.7 & & & 0.013 & 0.013 & -
\end{tabular}

центре соленоида при токе 50 А в его витках составляла величину $0.094 \mathrm{~T}$. Датчик Холла может перемещаться в радиальном $(r)$ и вертикальном $(z)$ направлениях. Он измеряет осевую составляющую $B_{z}$ магнитного поля ВТСП катушки и/или намагничивающего соленоида. Все описанные в настоящей статье эксперименты проводились на данной установке.

Постоянная времени $\tau$ ВТСП катушек (см. таблицу) измерялась следующим образом. Теплая ВТСП катушка, находящаяся в стакане с теплоизолирующими стенками, помещалась внутрь соленоида. Затем в витках соленоида устанавливался ток 50 А; в стакан с ВТСП катушкой заливался жидкий азот; катушка охлаждалась в течение 2 min до температуры жидкого азота; после этого ток соленоида в течение нескольких десятков секунд доводился до нуля. Начиная с момента, когда ток в витках соленоида обращался в нуль, датчик Холла измерял зависимость величины захваченного магнитного поля в центре ВТСП катушки от времени. Постоянная времени ВТСП катушки $\tau$ определялась как интервал времени, за который величина поля спадает в $e=2.71$ раза. Измеренные значения постоянных времени ВТСП катушек даны в таблице. Они лежат в интервале $\tau=18-35 \mathrm{~min}$. Каждый эксперимент по левитации с лабораторной моделью квадруполя выполняется в течение нескольких минут, поэтому ВТСП катушки с такими $\tau$ пригодны для их проведения. Индуктивность ВТСП катушек рассчи-

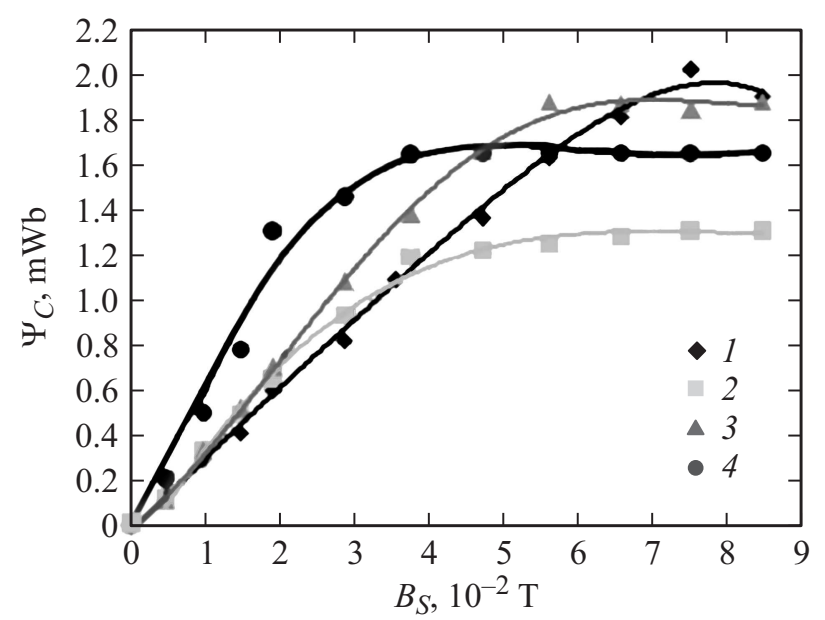

Рис. 3. Зависимости потокосцепления $\Psi_{C}$, захваченного ВТСП катушкой, от поля $B_{S}$ в центре соленоида для различных ВТСП катушек: 1 - ВТСП катушка № 1,2 - № 2, 3 - № 3, 4 № 4. тывалась с помощью программы для расчета магнитных полей FEMM. По величине индуктивности и времени спада $\tau$ рассчитывалось сопротивление катушек. Оно оказалось на уровне $20-0 \mathrm{n} \Omega$.

Захваченный ВТСП катушками магнитный поток был измерен при различных значениях магнитного поля намагничивающего соленоида. Ток в ВТСП катушках возбуждался путем их охлаждения в магнитном поле соленоида, как это описано выше. Измерение радиального распределения индукции $B_{z}$ магнитного поля, захваченного ВТСП катушками, начиналось сразу же после выключения тока в витках намагничивающего соленоида. Время измерений не превышало $3 \mathrm{~min}$. C учетом постоянной времени спада $\tau$ захваченного ВТСП катушками поля ( 20-30 min) ошибка в измерении захваченного ими магнитного потока не превышала $10 \%$. Измерения компоненты $B_{z}$ проводились в радиальном направлении на расстоянии $1 \mathrm{~mm}$ от торцевой поверхности ВТСП катушки перпендикулярно к оси катушки через каждые $2 \mathrm{~mm}$. По этим значениям были рассчитаны магнитные потоки $\Phi$ и потокосцепления $\Psi_{C}$, захваченные ВТСП катушками при различных значениях магнитного поля $B_{S}$ в центре соленоида. Полученные для ВТСП катушек № $1-4$ зависимости $\Psi_{C}$ от $B_{S}$ представлены на рис. 3.

Из рис. 3 видно, что при увеличении магнитного поля соленоида $B_{S}$ значение захваченного ВТСП катушками потокосцепления $\Psi_{C}$ выходит на насыщение. Их максимальные значения для всех ВТСП катушек даны в таблице. Из таблицы видно, что значения $\Psi_{C}$ для многовитковых короткозамкнутых катушек из ВТСП ленты намного превосходят поток, захваченный цельным ВТСП кольцом (№ 5), изготовленным с помощью метода MTG. По максимальным значениям захваченного ВТСП катушками поля были рассчитаны экспериментальные значения $I_{C E X}$ критического тока в них. Эти значения в таблице сравниваются с паспортными значениями $I_{C P}$ критического тока. Величина $I_{C E X}$ составляет $\sim 50 \%$ от $I_{C P}$.

\section{2. Исследование сохранения ВТСП катушками захваченного магнитного потока}

Способность катушки из сверхпроводника сохранять захваченный магнитный поток лежит в основе создания 


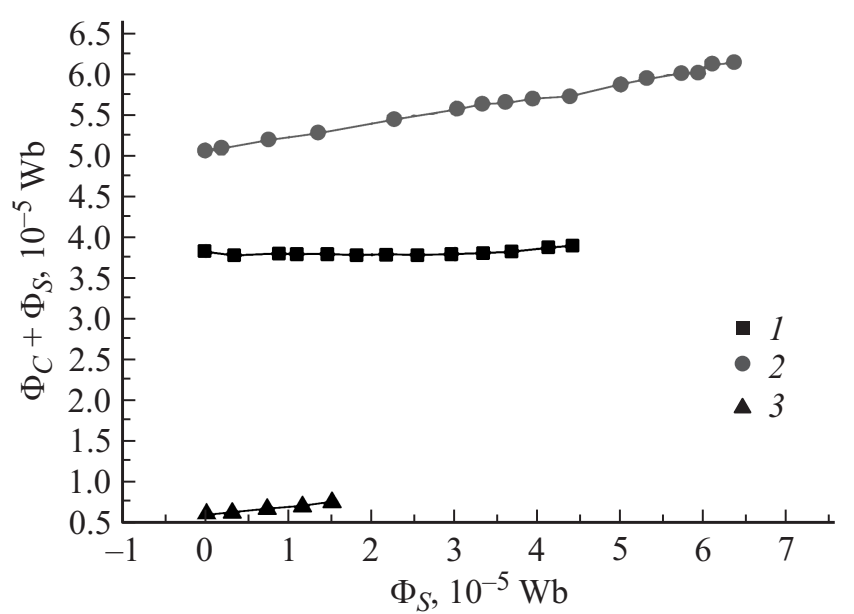

Рис. 4. Зависимости суммарного магнитного потока через сечение ВТСП катушки (либо ВТСП кольца) от потока, создаваемого через это сечение соленоидом: 1 - ВТСП катушка № 1,2 - № 3, 3 - № 5 .

левитирующих систем без обратных связей [7-12]. Изучение способности ВТСП катушек сохранять магнитный поток выполнялось с помощью установки, схема которой приводится на рис. 2.

Теплая ВТСП катушка, находящаяся в стакане с теплоизолирующими стенками, помещалась внутрь соленоида 1. Затем в витках соленоида устанавливался ток $12 \mathrm{~A}$ (что соответствует полю в центре соленоида $\left.2.25 \cdot 10^{-2} \mathrm{~T}\right)$. Катушка охлаждалась в течение $2 \mathrm{~min}$ до температуры жидкого азота. Ток соленоида уменьшался до нуля. В результате в ВТСП катушке возбуждался сверхпроводящий ток, создававший остаточное магнитное поле. После этого ток в витках соленоида увеличивался от 0 до $12 \mathrm{~A}$ и снова уменьшался до 0 А. При изменении тока соленоида в таких пределах сверхпроводящий ток в ВТСП катушках был ниже критического значения $I_{C E X}$. Датчик Холла измерял суммарное магнитное поле катушки и соленоида в их общем центре. Для получения магнитного поля $B_{C}$, создаваемого сверхпроводящим током ВТСП катушки в ее центре, из суммарного поля вычиталось поле соленоида $B_{S}$. Величина $B_{S}$ определялась по величине тока в витках соленоида, снимаемого с калиброванного шунта 6 на pис. 2. Измерив $B_{C}$ и магнитный поток $\Phi_{C}$, захваченный ВТСП катушкой, для одного из значений токов в ВТСП катушке, мы нашли коэффициент пропорциональности между ними для каждой из ВТСП катушек, что позволило рассчитывать $\Phi_{C}$ по значениям $B_{C}$. Магнитный поток соленоида $\Phi_{S}$ оценивался как произведение $B_{S}$ на площадь ВТСП катушки. Затем поток катушки складывался с потоком соленоида, и строилась зависимость суммарного потока $\Phi_{C}+\Phi_{S}$ от потока соленоида $\Phi_{S}$. Полученные результаты приведены на рис. 4. Из рисунка видно, что для ВТСП катушки № 1 (кривая 1) суммарный поток остается постоянным, и изменения суммарного потока для ВТСП катушки № 3 (кривая 2) и керамического кольца № 5 (кривая 3) лежат в пределах ошибки измерений и расчетных приближений.

Таким образом, катушки из ВТСП ленты и ВТСП кольца сохраняют захваченный магнитный поток в диапазоне полей намагничивающего соленоида, где потокосцепление $\Psi_{C}$ прямо пропорционально $B_{S}$ и сверхпроводящий ток в ВТСП катушках меньше $\sim 0.7 I_{C E X}$.

С помощью установки, схема которой приведена на рис. 2, для ВТСП катушек № 1-4 и ВТСП кольца № 5 были также измерены зависимости $B_{C}$ (поля в центре ВТСП катушки) от $B_{S}$ (поля в центре намагничивающего соленоида) при циклическом изменении поля соленоида. ВТСП катушка (либо ВТСП кольцо), находящаяся в стакане с теплоизолирующими стенками, помещалась в соленоид 1. Затем ВТСП катушка охлаждалась в течение $2 \mathrm{~min}$ до температуры жидкого азота. После чего ток в соленоиде изменялся в такой последовательности: $0 \mathrm{~A} \rightarrow 5 \mathrm{~A} \rightarrow 0 \mathrm{~A} \rightarrow(-5 \mathrm{~A}) \rightarrow 0 \mathrm{~A}$. Этот процесс повторялся для амплитуд токов 10,15 ,
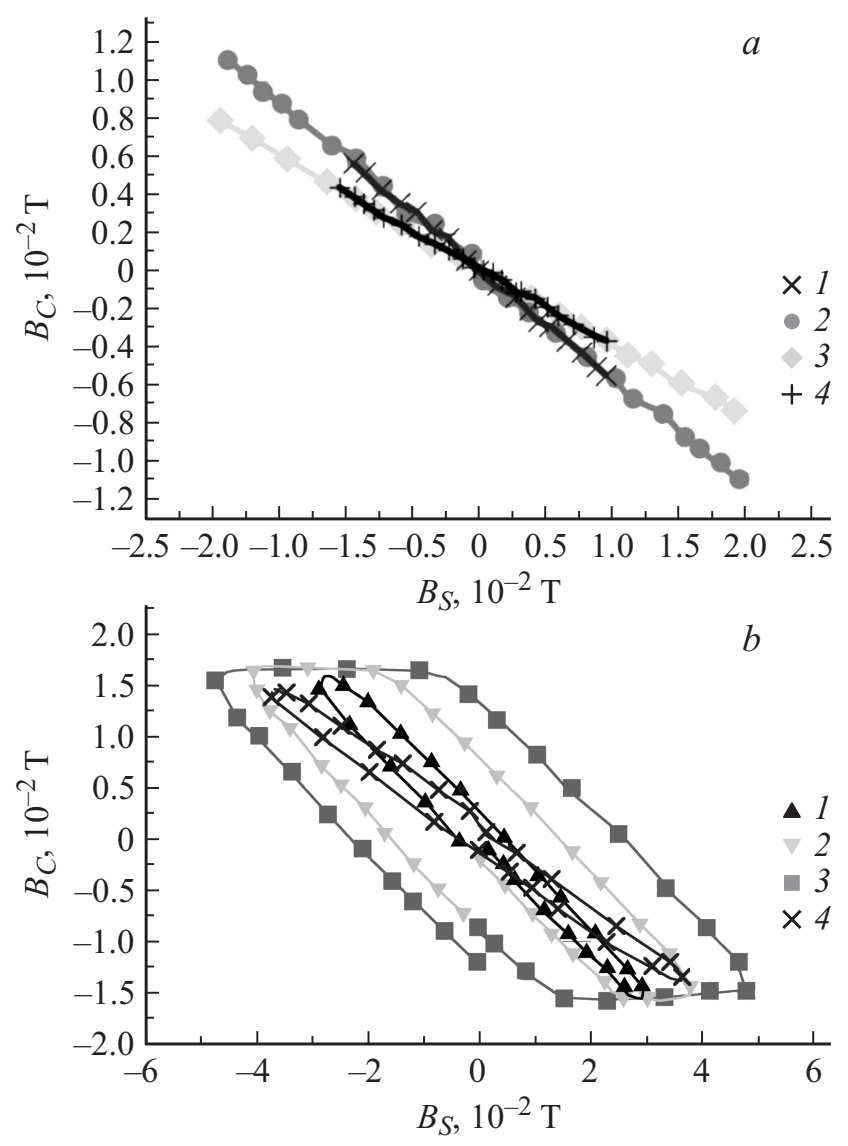

Рис. 5. Зависимости магнитного поля $B_{C}$ в центре ВТСП катушки от магнитного поля $B_{S} \quad$ в центре намагничивающего соленоида: $a-1,3-$ ВТСП кольцо № 5; 2,4 - ВТСП катушка № 4; 1,4 - ток соленоида: $0 \mathrm{~A} \rightarrow 5 \mathrm{~A} \rightarrow 0 \mathrm{~A} \rightarrow(-5 \mathrm{~A}) \rightarrow 0 \mathrm{~A} ; 2,3-$ ток соленоида: $0 \mathrm{~A} \rightarrow 10 \mathrm{~A} \rightarrow 0 \mathrm{~A} \rightarrow(-10 \mathrm{~A}) \rightarrow 0 \mathrm{~A} ; b-1,2,3-\mathrm{BTC}$ катушка № 4; 4 - ВТСП кольцо № 5; ток соленоида: $1-0 \mathrm{~A} \rightarrow 15 \mathrm{~A} \rightarrow 0 \mathrm{~A} \rightarrow(-15 \mathrm{~A}) \rightarrow 0 \mathrm{~A} ; 2-0 \mathrm{~A} \rightarrow$ $20 \mathrm{~A} \rightarrow 0 \mathrm{~A} \rightarrow(-20 \mathrm{~A}) \rightarrow 0 \mathrm{~A} ; 3-0 \mathrm{~A} \rightarrow 25 \mathrm{~A} \rightarrow 0 \mathrm{~A} \rightarrow$ $(-25 \mathrm{~A}) \rightarrow 0 \mathrm{~A} ; 4-0 \mathrm{~A} \rightarrow 20 \mathrm{~A} \rightarrow 0 \mathrm{~A} \rightarrow(-20 \mathrm{~A}) \rightarrow 0 \mathrm{~A}$. 
20 и 25 А. Одновременно записывались два сигнала: с датчика Холла, измерявшего суммарное поле ВТСП катушки (либо кольца) и соленоида в их общем центре, и с шунта 6, измерявшего ток в витках соленоида. После обработки полученных данных были построены графики $B_{C}$ от $B_{S}$. На рис. 5 эти зависимости приводятся для ВТСП катушки № 4 и ВТСП кольца № 5. Графики для ВТСП катушек № 1-3 аналогичны графику для ВТСП катушки № 4. Из сравнения кривых на рис. 5 следует, что зависимости $B_{C}\left(B_{S}\right)$ для ВТСП колец и ВТСП катушек имеют сходный характер. Выход на насыщение кривой $B_{C}\left(B_{S}\right)$ определяется значением критического тока $I_{C E X}$.

\section{Заключение}

Проведенные измерения показали, что катушки из ВТСП ленты и ВТСП кольца, полученные методом MTG, сохраняют захваченный магнитный поток в определенном диапазоне изменения внешнего поля. Использование этих данных позволит найти по аналитическим зависимостям [7-12] устойчивые состояния ВТСП катушек лабораторной модели левитирующего квадруполя и экспериментально осуществить их без использования обратных связей.

Исследование выполнено при поддержке Министерства образования и науки РФ, Задание № 3.5160.2017/БЧ и при частичной финансовой поддержке РФФИ, грант № 13-08-00717.

Авторы выражают признательность к.ф.-м.н. И.Ф. Волошину за полезные советы по технологии изготовления короткозамкнутых ВТСП катушек.

\section{Список литературы}

[1] Морозов А.И., Савельев В.В. // УФН. 1998. Т. 168. № 11. C. 1153-1194.

[2] Бишаев А.М., Бугрова А.И., Гавриков М.Б., Козинщева М.В., Липатов А.С., Савельев В.В., Сигов А.С., Смирнов П.Г., Тарелкин И.А., Храмщов П.П. // ЖТФ. 2013. Т. 83. Вып. 4. С. 34-40.

[3] Schultz J.H., Driscoll G., Garnier D., Kesner J., Mauel M., Minervini J.V., Smith A., Radovinsky A., Snitchler G., Zhukovsky A. // IEEE Trans. Appl. Supercond. 2011. Vol. 11. N 1. P. 2004-2009.

[4] Boxer A.C., Bergmann R., Ellsworth J.L., Garnier D.T., Kesner J. et. al. // Nature Physics. 2010. Vol. 6. P. 207-212.

[5] Saitoh H., Yoshida Z., Morikawa J., Yano Y., Mizushima T., Kobayashi M. // J. Fusion Energ. 2010. Vol. 29. N 6. P. 553557.

[6] Yano Y., Yoshida Z., Ogawa Y., Morikawa J., Saitoh H. // Fusion Eng. Des. 2010. Vol. 85. N 5. P. 641-648.

[7] Бишаев А.М., Буш А.А., Гавриков М.Б., Козинцева М.В., Каменцев К.Е., Савельев В.В., Сигов А.С. // Письма в ЖТФ. 2012. Т. 38. Вып. 19. С. 23-29.

[8] Бишаев А.М., Буи А.А., Гавриков М.Б., Козинцева М.В., Каменщев К.Е., Савельев В.В., Сигов А.С., Денисюк А.И., Гордеев И.С. // ЖТФ. 2013. Т. 83. Вып. 5. С. 61-68.
[9] Bishaev A.M., Bush A.A., Behtin M.A., Gavrikov M.B., Gordeev I.S., Bugrova A.I., Kamentsev K.Ye., Kozintseva M.V., Savel'ev V.V., Safronov A.A., Shaposhnikov M.I., Smirnov P.G. // Problem. Atom. Sci. Technol. 2013. N 1 (83); Ser. Plasm. Phys. 2013, N 19. P. 48-50.

[10] Битаев А.М., Буш А.А., Гавриков М.Б., Денисюк А.И., Каменцев К.Е., Козинцева М.В., Савельев В.В., Сигов А.С. // ЖТФ. 2014. Т. 84. Вып. 6. С. 155-158.

[11] Bishaev A.M., Bush A.A., Gavrikov M.B., Denis'uk A.I., D'yakonitsa O.Y., Kamentsev K.Ye., Kozintseva M.V., Kolesnikova T.G., Savelyev V.V., Smirnov P.G., Shapovalov M.M., Voronchenko S.A. // Problem. Atom. Sci. Technol. 2015. N 1 (95). Ser. Plasma Phys. 2015. N 21. P. 16-19.

[12] Бимаев А.М., Буи А.А., Гавриков М.Б., Каменцев К.Е., Козинцева М.В., Савельев В.В., Сигов А.С. // ЖТФ. 2015. T. 85. Вып. 11. С. 137-140.

[13] Vanderbemden Ph., Cloots R., Ausloos M. // IEEE Trans. Appl. Supercond. 1999. Vol. 9. N 2. P. 2308-2311.

[14] Электронный ресурс. Режим доступа: http://www.superpower-inc.com/content/2g-hts-wire

[15] Zheng X.G., Matsui H., Tanaka S., Suzuki M, Xu C.N. // Proc. of the $11^{\text {th }}$ Int. Symposium on Superconductivity. Fukuoka: Japan, 1999. Vol. 1. P. 451-456. 